\title{
2
}

\section{Acquainted with All that Is Great and Good: Designing a Twenty-First Century Curriculum}

Governments round the world and coordinators and curriculum developers of systems of education such as the European School System at the end of the twentieth century and in the early part of the twenty-first century, with a few notable exceptions, have reached an agreement about the nature of the school curriculum, learning approaches and assessment practices. This consensus now operates at all levels of education systems, and can be expressed in terms of a number of propositions: traditional knowledge forms and strong insulations between them need to be preserved; each of these knowledge forms can be expressed in terms of lower and higher level domains and the latter have to be taught before the former and sequenced correctly; certain groups of children are better able to access the curriculum than other children, and, as a result, a differentiated curriculum is necessary to meet the needs of all school learners; the teacher's role is to impart this body of knowledge in the most effective way, and thus their brief cannot concern itself with the ends to which education is directed, but only the means for its efficient delivery; and the school's role is to deliver a public service that meets the targets set for it by governments and other such educational systems.

The most important element of the European School System is its curriculum, and therefore we need in the first instance to understand what a 
curriculum is. A curriculum points to what is intended should happen in a programme of learning and the circumstances in which these activities can take place. Those activities are learning activities; and thus a curriculum is a collection of exercises and tasks, which culminate in learning of one type or another. There are three types of learning: cognitive, skillbased and dispositional, and they have different forms and operate in different ways. Cognition is the manipulation of those symbolic resources (words, numbers, pictures etc.) that points to something outside itself. Skill-based knowledge is procedural and not declarative; and dispositional knowledge refers to relatively stable habits of mind and body, sensitivities to occasion and participation repertoires. Significantly, these three types of learning are focused on knowledge-construction and are knowledge-development activities, although there are some important differences between the three types. And what can be inferred from this is that how knowledge is construed will determine how appropriate learning environments are constructed and ultimately how learners then learn in and from them.

The learning aims and objectives of a curriculum do not specify how the knowledge, skills, and dispositions should be taught, though teaching and learning approaches are derived from them. As a consequence the curriculum-developer needs to reconceptualise each intended learning outcome into a programme of learning or action learning set. Pedagogic approaches and strategies range from didactic to imitative to reflective and meta-reflective action learning sets, and they have a number of common characteristics. A pedagogic approach specifies: the circumstances in which it can be used in the learning environment; the resources and technologies which allow that learning to take place; the type of relationship between teacher and learner, and learner and learner, to effect that learning; a theory of learning, or, in other words, a theory of how that construct (i.e. knowledge set, skill or disposition) can be assimilated; and a theory of transfer held by the teacher, that is, how the learning which has taken place in a particular set of circumstances (i.e. a classroom, with a set of learners, in a particular way, with a particular theory of learning underpinning it, and so forth) can transfer to other environments in other places and times. Paying due attention to these allows a proper focus on learning, with these being generally neglected in the various iterations of 
the curriculum in the European School System (both those proposed and those implemented).

Pedagogic arrangements also need to fit with the view of knowledge held by the curriculum-developer. To this end, curriculum decisions need to be made about: pedagogic approaches and strategies (i.e. observation; coaching; goal-orientated learning; mentoring; peer-learning; simulation; instruction; concept-formation; reflection; meta-cognitive learning; problem-solving and practice); relations between knowledge domains (i.e. traditional/fragmented or networked/fully integrated modes); knowledge, skill or dispositional orientations; knowledge framings; progression and pacing; types of relations between teachers and students; relations between types of learners; spatial and temporal arrangements for learning; formative assessment and feedback processes; and the criteria that can be used for evaluating learning. All these need to be taken into account in translating curriculum knowledge into pedagogic knowledge.

Learning aims, objectives and prescriptions, or curriculum standards (i.e. learning objects), are therefore distinguished from these pedagogic approaches and also from assessment arrangements. Frequently, an assessment procedure specifies those knowledge-sets, skills or dispositions that a learner is required to have, and which are expressed in such a way that they can be tested in a controlled environment, such as an examination. The principal problem with assessment procedures of this type is that testing a person's knowledge, skills and dispositions is likely to have washback effects on the original set. Instead of the assessment process acting merely as a descriptive device, it also acts in a variety of ways to transform the curriculum it is seeking to measure. Washback effects work on a range of objects and in different ways. So, for example, there are washback effects on the curriculum, on teaching and learning, on the capacity of the individual and more fundamentally on the structures of knowledge, though these four mechanisms are frequently conflated in the minds of educational stakeholders. Micro washback effects work directly on the person, whereas macro washback effects work directly on institutions and systems, which then subsequently have an impact on individuals within those institutions and systems. Finally, a learner may have to reframe their knowledge or skill set to fit the test, and therefore the assessment of 
their mastery of this knowledge or skill is not a determination of their competence, but of whether they have successfully understood how to rework their capacity to fit the demands of the examination technology. As a result teaching to the test occurs and the curriculum is narrowed to accommodate those learning outcomes that can more easily be assessed. There is some evidence of this occurring in the European Baccalaureate.

The reason for separating out learning approaches from assessment approaches is now clear. If these assessment approaches are the same as learning approaches, then this is likely to have a detrimental and reductionist effect on the curriculum and more importantly on the type and content of learning that takes place. However, there are different needs within a system of education, and one of these is that, at set points in time, supra-national (such as the European Commission), national and local educational bodies need to have information about how well the system is doing. This is a very different process from improving learning with an individual learner. However, there must be some connecting link between learning and reporting, so that the latter doesn't distort the former, and this is the role of learning aims and objectives.

Learning and assessment practices on a programme of study, such as a curriculum, can be regarded as formative if evidence of a learner's achievements in relation to knowledge and skill acquisition is collected and used by the teacher, the individual student, and their fellow students, with the specific intention of deciding on their subsequent programme of learning. As a result, assessment is used formatively when it directly influences the learner's cognition. Curriculum developers consequently need to make a clear distinction between summative and formative assessment. If these two functions are combined, then the potential impact of the curriculum is weakened.

There are two principles which structure the choice and order of content within a curriculum: a spiral element or a re-visiting of concepts, skills or dispositions at a higher level of intensity and at a later point in the programme of study, and theory transfer from theory to practice and from sites of learning to sites of application. The first of these is the need to incorporate a spiral element into the curriculum, i.e. a set of ideas or operations, once introduced, is revisited and reconstructed in a more formal or operational way, at different stages in the learning programme (cf. 
Bruner 1996). And the second refers to the relationships between experience, theory- or concept-development (in the three different domains of knowledge, skill and disposition), strategies for the application of this theory or set of concepts, applications of these learning and practice skills, strategies and plans for action, and evaluations of these practices for the purpose of changing them. The effect is to move the learner into the centre of the practice and away from the periphery.

In order for learning to take place, i.e. increased levels of knowledge, enhanced skill levels and dispositional improvements, the following are important considerations: a minimisation of washback effects; an emphasis on curriculum, rather than assessment-driven change; the preservation of the curriculum as the principal driver of the learning programme rather than that which can be most easily assessed; a clear separation of the evaluative and learning functions in any educational programme; and an intelligible set of curriculum specifications, expressed as learning standards or objects. Though the European School System is better than most other systems in mitigating these harmful effects, there are regressive elements relating to these matters in the current arrangements.

A further point needs to be made about the construction of a curriculum and this refers to how progression is understood within the domains of knowledge from which it has been derived. (This is disciplinary knowledge.) Many curricula round the world employ progression modes that are extensional in design, where this is understood as an increase in the amount, or range, of an activity, whether knowledge-based, skill-oriented or dispositional. This has the effect of limiting, and distorting, the notion of progression, both between items in a curriculum and in terms of the progress a learner makes within that curriculum.

There are a number of other forms of progression and they need to be incorporated into the design of the curriculum. The first of these is prior condition. In the acquisition of particular knowledge, skill and dispositional elements, there are prerequisites in the learning process. A second is maturational, where this refers to the physical development of the mind of the learner. A third is intensification. Whereas extension refers to the amount or range of progression, intensification or complexity refers to the extent to which a sophisticated understanding has replaced a superficial understanding of a concept. In relation to the knowledge constructs, 
skills and dispositions implicit within the curriculum, there are four forms of complexity that might signify progression. These are behavioural complexity, symbolic complexity, affective complexity and perceptual complexity. There is also a type of progression, abstracting, which involves moving from a concrete understanding of a concept to a more abstract one. A further type of progression is an increased capacity to articulate, explain or amplify an idea or construct, i.e. the learner retains the ability to deploy the skill, and in addition, they can now articulate, explain or amplify what they are able to do and what they have done. And finally progression can be understood as part of a process, and this refers to the way that the learner interacts with the learning object. An example could be moving from an assisted performance to an independent one. This suggests that curricula as they are presently conceived round the world are deficient if they employ extensional forms of progression exclusively at the expense of a range of other types. These forms of progression are not of the same order; however, they refer to different aspects of the process of learning. There is no category error here. They are linked by their capacity to affect different parts of the learning process, and in particular, where an individual moves from one state of being to another. For example, extensional forms of progression focus on the objects of learning, whereas process forms of progression focus on the learner and the way they can and do respond to these objects.

Over the last fifty years, there has been a move away from traditional/ fragmented approaches towards networked approaches in some school curricula. There are implications of adopting either fragmented or networked approaches or taking up positions in between. A fragmented or traditional approach fits better with how universities, teachers, parents and students understand curricular divisions at school level; allows choice between subject options whilst retaining core subjects; better reflects current arrangements; and can be better accommodated within traditional pedagogic structures. A networked approach reduces choice because it implies that all aspects of the curriculum have to be covered in the teaching and learning arrangements that are put in place; and may better reflect the nature of subject knowledge. The key question is how to balance these imperatives when undertaking a reform of secondary education in a system such as the one we are focusing on in this book. Thus, 
there are significant implications of some of these ideas for the curriculum of the European School System, for the constitution of the European Schools Baccalaureate and in particular, for the Baccalaureate rules. There are also implications for higher education access from these schools to European universities.

\section{The European Schools Curriculum}

Both the system of European schools and the process of widening access to the European Baccalaureate with regards to three categories of schools are built on the idea that the whole system shares a common pedagogical ethos. The 'opening up' that we referred to earlier is based on the idea that the notion of European schooling is a particular, exportable and replicable type of education. This is currently organised through a centralised system that gives the Board of Governors the authority to set, correct and adapt the common criteria of evaluation. Such criteria were established in 2005 and are updated periodically.

In February 2012 the Joint Teaching Committee, which is the institution with a mandate to oversee all the pedagogical issues of the European Schools System, adopted the following document: 'New Structure for all Syllabuses in the System of the European Schools' (cf. Board of Governors 2012). This document illustrates the path that the European Schools System is taking in terms of pedagogical development. It adopts a common structure for all the syllabuses, and identifies two objectives for the system:

The European Schools have the two objectives of providing formal education and of encouraging students' personal development in a wider social and cultural context. Formal education involves the acquisition of competences - knowledge, skills and attitudes - across a range of domains. Personal development takes place in a variety of spiritual, moral, social and cultural contexts. (Board of Governors 2012: 3)

Here implicit reference is made to the multicultural environment of the European Schools System: 
The students of the European Schools are future citizens of Europe and the world. As such, they need a range of competences if they are to meet the challenges of a rapidly-changing world. In 2006 the European Council and European Parliament adopted a European Framework for Key Competences for Lifelong Learning. It identifies eight key competences which all individuals need for personal fulfilment and development, for active citizenship, for social inclusion and for employment: communication in the mother tongue; communication in foreign languages; mathematical competence and basic competences in science and technology; digital competence; learning to learn; social and civic competences; sense of initiative and entrepreneurship; and cultural awareness and expression. The European Schools' syllabuses seek to develop all of these key competences in the students. (Board of Governors 2012: 3)

Significantly, the pedagogical objectives of the European schools are defined on the basis of the European Framework for Key Competences, as adopted by the European institutions.

The new common structure in terms of pedagogy emphasises the will to connect the European schools with the educational policy of the European Union. The document that emerged from the Joint Teaching Committee makes official the link between the notion of European schooling, as developed by the European schools, and the educational policy of the European Union (cf. Board of Governors 2012), as we can see in the introductory sentence of the document:

The underlying concept of this structure expresses a change from the contents-oriented syllabus to a competence-based syllabus. The structure of the syllabus is intentionally brief and precise. (Board of Governors 2012: 3)

The tendency to bring closer the pedagogical objectives of the European schools with the European Union is also emphasised in the Alicante Declaration on European Schooling made by Interparents, in April 2012, and in particular in point 14 where parents:

(a)sk that Member States' determination to invest in the development of quality education, youth and mobility, cultural and linguistic diversity, the European dimension and citizenship as well as a global perspective, Europe 2020-strategy and lifelong learning goals also apply to European Schools. (Board of Governors 2012) 
The Alicante declaration identifies directly those issues that are considered to be the bedrock of the educational agenda at the European level: the 2020 strategy and the concept of life-long learning.

The strategy to align the type of pedagogical curriculum offered at the European schools with the educational policies set by the European institutions is also evident in the changes that were introduced to the European Baccalaureate. When the Board of Governors adopted the final report of the working group, Reform of the European Baccalaureate, it was agreed that the marking/grading criteria would be inspired by the European Credit Transfer System, which is precisely the marking criterion used by the European Union at the postgraduate level.

The secondary level in European schools comprises seven years. In the first three years all students follow a common course, known as the observation cycle. The majority of the subjects are still taught in the language corresponding to each language section. In the second year of secondary school the learning of a second language, which was already an option at the primary level, is compulsory. In the third year all students take geography and history in the foreign language they have chosen (which is often referred to in the system as the 'working language', or 'langue véhiculaire'). The system offers three working languages (which correspond to the working languages of the European Union): French, English and German.

In secondary years four and five (S4-S5) the compulsory course in science includes physics, chemistry and biology, as well as mathematics. New options are made available from the fourth year, such as economics, a third foreign language and ancient Greek. The last two years, six and seven (S6-S7), form a unit leading to the European Baccalaureate. The compulsory courses include: a national language, L2, mathematics, a science, philosophy, physical education, history and geography. During the years of preparation for the Baccalaureate students choose from a range of options, and they may decide to study some of the compulsory courses as a two period course or at the advanced level as a four period course.

In Geography the principal emphasis is on the European Union. The teachers are also expected to provide historical material for their students relating to the European Union and its institutions, and to discuss the various ways with them in which Europe can be defined, including the natural environment, demography, industry and energy, rural environment, regional 
policies, etc. The arts and the humanities have a special place in the curriculum, and music is of particular importance. The programme 'has the responsibility for delivering one of the key objectives of the European Schools which is to provide young people with opportunities for creative endeavour and to promote an understanding of a common European heritage' (Board of Governors 2012: 2).

There is a multi-cultural element running through the curriculum. Banks (2007: 139) identifies five dimensions of multicultural education: content integration (using examples and content from a variety of cultures in the teaching); knowledge construction (teachers help students understand the implicit cultural assumptions); prejudice reduction (ethnic, social, economic, nationalist); an empowering school culture; and finally, an equity pedagogy (where teachers modify their teaching in ways that facilitate the academic achievement of students). Of those five dimensions, the European schools prioritise two: content integration and knowledge construction. The curriculum is constructed in order to create an equality of esteem between the different European cultures. This is achieved, for example, by providing transnational examples in the geography or history programmes at the secondary level and by providing at an early age several pedagogical frameworks associated with a common European culture. Furthermore, multilingualism is given a prominent role in the curriculum. Allemann-Ghionda (2012: 126) suggests that 'multilingual education is regarded as a privileged path of intercultural education $[. .$.$] , their pedagogies are based on the assumption that acquir-$ ing a deep knowledge and an active command of languages other than one's mother tongue has the effect of expanding the mind and enhancing intercultural competence'.

\section{Subjects}

Writings about what makes for a good science or mathematics curriculum largely rely on conceptual work and professional wisdom. We lack high quality, large-scale evaluations that rigorously test interventions. For this reason an evidence-based research synthesis (let alone any sort of systematic review) is simply not possible (e.g. Watson et al. 2013, with 
regards to mathematics). Nevertheless in both science education and mathematics education there is a growing body of evidence-informed work about what makes for a good curriculum. Perhaps the most fundamental issue is that of content. In science education there has been a growing acknowledgement in recent times that many school curricula are overloaded. Too much time is spent covering a myriad of specific, often isolated, pieces of content with the result that the larger picture is lost.

It is clearly important to have a curriculum that facilitates, or at the very least enables, students to progress in their learning as best they can. Studies on students' progression in learning (whether in mathematics, in science or more generally) have often been interpreted as though learning progresses up a ladder or in stages, so that each rung of the ladder (or stage) needs to be reached before subsequent progression can occur. Unsurprisingly, fine-grained observations of students' learning, such as those by Shapiro (1994), reveal that learning is rarely like this. Not only do learners sometimes regress, they also at times miss a stage (or rung on the ladder). The implication for curriculum developers is that concepts need to be ordered in a logical sequence that facilitates learning but it should not be assumed that learning proceeds inflexibly along such a route. Learning can be more like putting together the pieces of a jigsaw, where this can be done successfully in a number of ways rather than in one predetermined order. It is generally agreed in curricula round the world that mathematics and science should be core subjects.

Given this, there are a number of important considerations as to which subjects should be taught in the European Schools' curriculum. Parents and students will invariably bring their own understandings about curriculum planning to any discussion of a reform process. This means that if parents hold traditional views about subjects within a curriculum, for example, that there needs to be three separate sciences (i.e. physics, chemistry and biology), then it follows that, as far as they are concerned, a general science curriculum is going to appear incomprehensible or, in their view, represent a simplification and thus reduction in the quality of this important area of the curriculum. It doesn't matter whether parents are correct in their judgements about the subject make-up of the curriculum, their beliefs are significant factors in any decisions made by European school curriculum-makers, and need to be taken into account accord- 
ingly. A system that overrides the views of those closely involved on a day-to-day basis is unhelpful and unresponsive, and any reforms are unlikely to work in practice.

Teachers will also bring their own understandings of curriculum planning to any debate. This has the same effect as with parents, though teachers approach the problem from a different angle. Their perspective emanates from longstanding and perhaps strongly held beliefs about curricular divisions, their own disciplinary perspective (i.e. their university subject and their pedagogical training in that subject) and the syllabuses and curricula they have been teaching for, in some cases, many years. Again, effective reform is impossible without adequate teacher engagement and support, so teachers' views need to be taken seriously.

Specifications for the system from the Board of Governors also play an important part in the debate. These are perhaps best summarised in Article 4 of the Convention:

1. The courses of study shall be undertaken in the languages specified;

2. Certain subjects shall be taught to joint classes of the same level;

3. A particular effort shall be made to give students a thorough knowledge of modern languages;

4. The European dimension shall be developed in the curricula;

5. The conscience and convictions of individuals shall be respected; and

6. Measures shall be taken to facilitate the reception of children with special educational needs.

Article 4 is legally enshrined in the constitution of the European Union.

The European Commission has identified eight key competences for lifelong learning as requirements for underpinning any curriculum reform process. These competences are: communication in the mother tongue; communication in foreign languages; mathematical competence and basic competences in science and technology; digital competence; learning to learn; social and civic competences; a sense of initiative and entrepreneurship; and cultural awareness and expression. In planning any curriculum reform, it is important to avoid subjects that do not have an overall rationale or are not exemplifications of the eight competences; 
otherwise the curriculum becomes an arbitrary collection of subjects. Subjects also need to fit with current and/or future arrangements for the Baccalaureate.

A further factor is university entrance. It should be noted that subjects that fall within traditional disciplinary boundaries are also more readily recognised by a range of university systems. However, universities may recognise these subject boundaries as subject divisions at the point of student entry, but arrange knowledge into subjects that do not conform to these traditional subject boundaries, i.e. only a very few universities currently divide their science provision into physics, chemistry and biology. It should also be noted that university entrance requirements can be variable, depending on the national system in operation, the apparent prestige of the university, how competitive course entry needs to be (for example medicine is an example of a highly competitive course), the type of entrance qualification for particular students, overall student numbers, and the length of time a course has been in operation. An important factor in any arrangement of subjects is therefore flexibility. Entry requirements for each of these degrees reflect the subject matter of the degree. The titles of the various degrees do not equate with the titles of the subjects offered currently in the European Schools System. These differences reflect both omissions and particular sets of combinations. They also reflect the type of university or institute of higher education, the various ways those institutions have combined subjects together, their institutional histories, and the availability of teaching staff and other resources. Likewise, the European Schools System's current arrangements reflect the history of the system, the availability of resources (including teacher resources) and the types of schools that have been developed. This means that there is no overall curriculum rationale for the selection of subjects and combinations of subjects in either the European Schools System or the European Higher Education System, though there is some attempt in both to be broad and comprehensive.

However, these differences between the overall European schools' curriculum (in terms of subjects offered) and the overall curriculum of European higher education institutions are not unexpected, and yet, breadth and comprehensiveness are mandated in the European Schools System by the Board of Governors. This is that the curriculum (including 
choice of subjects, relations between core, option and complementary subjects, length of instructional time given to each of those subjects, etc.) should reflect the eight core competences. Otherwise, decisions relating to choice of subjects, relations between those subjects, the content of those subjects, and the length of instructional time for these subjects become a matter of special pleading and are relatively arbitrary.

Philosophy is an example of this. A number of arguments have been put forward to support the idea that it should be central to the European schools' curriculum. Philosophy already forms a part of the Baccalaureates for France, Italy and Spain. Students applying to universities in these countries without philosophy as a component of their pre-university qualification are placed at a disadvantage. Some European citizens might think of a European Baccalaureate, which didn't include philosophy, as a second-class qualification. Indeed, philosophy provides a foundation for law, psychology, economics, theology, literature, history, geography, etc. and in addition is a coordinating and unifying subject in its own right. And further to this, philosophy is the only subject that allows students to consolidate and unify knowledge across the disciplines. Without philosophy in the curriculum as a compulsory subject, students graduate with fragmented packets of knowledge, and no framework that encompasses all the disciplines and allows them to develop a consistent, intellectual worldview. The philosophy syllabus therefore fills in critical gaps that exist in other parts of the European schools curriculum. For example, the philosophy course is the only place that students study civics, political theory, epistemology, philosophy of science, ethics etc. For many S6 and S7 year students, this helps them to make sense of the academic knowledge that they have acquired and creates a framework for their knowledge. In addition, philosophy fits well into the competency curriculum, being relevant to competences five, six, seven and eight: learning to learn; social and civic competences; sense of initiative and entrepreneurship; and cultural awareness and expression. These are powerful arguments for philosophy being central to the European schools' curriculum, and for being a core rather than optional subject, quite aside from any thoughts about university admissions requirements.

Latin is another example where it is relatively easy to make a strong case for its continued inclusion in the curriculum. A number of argu- 
ments have been developed as to why Latin should be a part of the curriculum. Students want to study it and thus limiting or eliminating it would restrict choice and diminish the possibilities for learning implied by offering choice to students, i.e. they are more likely to be motivated in their studies if they have some choice in what they study. Latin is the foundation for many European languages and thus studying Latin facilitates the learning of many of these languages. The language of Latin has cultural significance for European students. For those students who want to study ancient civilizations at European universities, studying Latin is particularly advantageous.

Disagreement about the content areas of the curriculum occurs in all subjects and religious education is no exception. However, controversy about the purpose of the religious education curriculum can be particularly intense. A well-established aim of much religious education is to maintain the faith of students in one particular religion or denomination (i.e. confessional religious education). Such an approach is often popular with certain parents who want to see a school promoting the same religious way of understanding the world that they provide in their homes. This aim is often found in what are typically referred to as faith schools (whether publicly or privately funded), by which is meant that one particular understanding of religious faith predominates. Proponents of this approach may argue that parents have a right to ensure that their children are educated within a particular religious framework or ethos.

As with philosophy, Latin and perhaps religious studies, we can see that a special case can be made for each of them as a core subject, or at least as an optional alternative, in the secondary curriculum. Yet the problem with maintaining student choice at the levels currently permitted, and (for example) maintaining instruction in particular subjects such as philosophy, religious studies or Latin, is that it has led to a very complex and diverse system with inconsistencies between schools. In some cases students are denied their first choices, or required to take subjects that they do not want to take. Currently, at S6 and S7 in the science specialisation, students are obliged to choose at least two options from biology, chemistry, ICT, physics and geography. Mathematics 5 is compulsory for students choosing physics. Human sciences are compulsory for those students not choosing geography. 


\section{Curriculum Alternatives}

We now sketch out three general alternatives: a curriculum without options, a curriculum with option choices within pathways, and a curriculum offering core and option subjects, and discuss each of these below. The first alternative is to eliminate options and teach elements of all the possible subjects that could be a part of the curriculum (and this would include subjects which currently are not offered in the European schools' curriculum such as psychology, linguistics, sociology, history of art, engineering, etc.) or are recognised as subjects by European universities (see Table 2.1). This could be achieved in a number of ways. General subject areas or pathways (and some of these are recognised in European university curricula) are created along the lines of the mandatory eight European competences, and all the possible subjects and all the subjects recognised by European universities are allocated to these areas. For example, instead of offering history (European or otherwise), geography, religious studies, ancient civilizations, literature, fine art and history of art, music history and appreciation, law, archaeology, architecture and philosophy, elements of these could come under the overall subject heading of humanities or cultural studies. Another example is social studies. So for example, instead of offering psychology, sociology, statistical science, economics, business studies and political science as options, elements of these are subsumed into a generic area of study or pathway, which could be called social studies or social sciences. A third example is natural sciences, and this would incorporate physics, chemistry, biology, biochemistry, biotechnology, technology, earth science, astronomy and medicine. What this effectively means is that weak boundaries are being established in the curriculum between subjects and that a more networked approach to curriculum design is being adopted.

In these three examples, students wouldn't choose between these subject areas, they would study all of them. However, unless more time was allocated to the teaching of the curriculum, this restricts the amount of time given to each of the subject areas (whether this is expressed as number of periods or as number of minutes of study). It delays specialisation of study by the student and effectively locates this decision at the point of entry to higher education. Such a proposal restricts content (defined as knowledge constructs, skills and dispositions within the subject disci- 
Table 2.1 An option-less curriculum

S1-S3 and S4-S5 (i.e. the first five years of secondary education)

Pathway 1 (Core): Communication - L1 Language and Literature

Pathway 2 (Core): First Modern Foreign Language - L2 Language and Literature

Pathway 3 (Core): Second Modern Foreign Language - L3 Language and Literature

Pathway 4 (Core): Humanities

Pathway 5 (Core): Performance and Expressive Studies

Pathway 6 (Core): Science

Pathway 7 (Core): Social Studies

Pathway 8 (Core): Mathematics

S6-S7 (i.e. the last two years of secondary education)

Pathway 1 (Core): Communication - L1 Language and Literature; Integrated

Themes: Reading, Writing, Speaking and Listening, Multi-modality, Knowledge about Language and Communication, ICT, and Language and Communication Dispositions

Pathway 2 (Core): First Modern Foreign Language - L2 Language and Literature; to include ONL Irish, Finnish, Maltese, Swedish; Integrated Themes: L2 Reading, L2 Writing, L2 Speaking and Listening, Knowledge about L2 Language and Communication, and L2 Language and Communication Dispositions

Pathway 3 (Core): Humanities; Integrated Themes: (These are not subjects but elements of subjects forming a Humanities Area of Study.) History, Geography, Religious Studies and Ethics, Ancient Civilizations, Fine Art and History of Art, Music History and Appreciation, Law, Archaeology, Architecture, and Philosophy

Pathway 4 (Core): Performance and Expressive Studies; Connected Themes: Music, Drama, Dance, Art and Design, and Physical Education

Pathway 5 (Core): Science; Integrated Themes: (These are not subjects but elements of subjects forming a Science Area of Study) Physics, Chemistry, Biology, Biochemistry, Biotechnology, Technology, including Computer Science, Earth Science, Astronomy, Medicine

Pathway 6 (Core): Social Studies; Integrated Themes: (These are not subjects but elements of subjects forming a Social Studies Area of Study.) Psychology, Sociology, Statistical Science, Economics, Business Studies, and Political Science

Pathway 7 (Core): Mathematics; Integrated Themes: Relations between quantities and algebraic expressions, Ratio and proportional reasoning, Connecting measurement and decimals, Spatial and geometrical reasoning, Reasoning about data, Reasoning about uncertainty, and Functional relations between variables

Pathway 8 (Core): Second Modern Foreign Language - L2 Language and Literature; to include ONL Irish, Finnish, Maltese, Swedish; Integrated Themes: L2 Reading, L2 Writing, L2 Speaking and Listening, Knowledge about L2 Language and Communication, and L2 Language and Communication Dispositions 
pline) for each subject area. However, depending on the way subject content is chosen, arranged and taught within the pathway, this should not be thought of as necessarily resulting in a weakening of each subject area.

A second alternative is to retain the six curriculum pathways but instead of offering social studies, humanities or science as generic areas of study, each pathway is broken down into four, five or six subjects. Each student then chooses one option from each of the pathways. This is a curriculum with option choices within pathways (see Table 2.2). So, in the social studies pathway, students would choose between psychology, sociology, statistical science, economics, business studies and political science, with each of these subjects retaining its identity. If it was considered

Table 2.2 An option within pathways curriculum

S1-S3 and S4-S5 (i.e. the first five years of secondary education)

Pathway 1 Communication - L1 Language and Literature

Pathway 2 First Modern Foreign Language - L2 Language and Literature

Pathway 3 Second Modern Foreign Language - L3 Language and Literature

Pathway 4 Humanities

Pathway 5 Performance and Expressive Studies

Pathway 6 Science

Pathway 7 Social Studies

Pathway 8 Mathematics

S6-S7 (i.e. the last two years of secondary education)

Pathway 1 (Option 1): Mother Tongue Language L1 - Choice between Language, Literature and ICT

Pathway 2 (Option 2): First Modern Foreign Language - L2 Language and Literature - Choice between all the different European languages

Pathway 3 (Option 3): Humanities - Choice between History, Geography, Religious Studies and Ethics, Ancient Civilizations, Fine Art and History of Art, Music History and Appreciation, Law, Archaeology, Architecture, and Philosophy

Pathway 4 (Option 4): Performance and Expressive Studies - Choice between Music, Drama, Dance, Art and Design, and Physical Education

Pathway 5 (Option 5) Science - Choice between Physics, Chemistry, Biology, Biochemistry, Biotechnology, Technology, Computer Science, Earth Science, Astronomy, Medicine

Pathway 6 (Option 6) Social Studies - Choice between Psychology, Sociology, Statistical Science, Economics, Business Studies, and Political Science

Pathway 7 (Option 7) Mathematics - Choice between Elementary and Advanced Mathematics

Pathway 8 (Option 8) Second Modern Foreign Language - Choice between all the different European languages 
that too small amounts of time or not enough lessons were being allocated to each subject, then the length of the school day could be increased to accommodate all the subjects being taught or time for one pathway could be increased at the expense of other pathways.

There are a number of advantages with this system. The eight competences are able genuinely to act as a guiding curriculum framework as they are mandated to. Students would be able to make better choices of which subjects they should study at university because they have studied one, or perhaps even two, subjects in each pathway. The curriculum of each individual student would have genuine breadth and be comprehensive in coverage. The problems associated with clashing options (i.e. having to choose between biology, ICT and geography when the student wants to study biology and ICT and has to settle for biology and history) and with option choices between subjects that are not compatible (i.e. choosing two options from biology, chemistry, ICT, physics and geography) would not exist. The principal disadvantage of this system is that coverage (i.e. exposure to the knowledge constructs, skills and dispositions) of the overall disciplinary pathway would be restricted (unless the amount of time given to the curriculum was increased). Further, this alternative and the first one would entail radical changes to the curriculum and there are extra costs and potential risks associated with it.

The third alternative is a mixture of core subjects and options (of different types and as having different relations with the core subjects), as in the current arrangements (see Tables 2.3 and 2.4). The organisation of secondary studies was the object of a broad reform in April 1990. Additional reforms to S1-S3, originally introduced as part of the current proposal for the reorganisation of secondary studies, were implemented in September 2014. The curricula for the three cycles in secondary school comprise, in differing proportions: core (compulsory) subjects, optional subjects and complementary subjects. For core subjects, non-viable group sizes are managed by grouping students across several levels (called 'vertical grouping') or across languages (called 'horizontal grouping'); if this is not possible teaching hours are reduced. A group is not considered viable if it has less than seven pupils for S1 to S5 and less than five for S6 and S7. Optional courses run in any given language only if there are a sufficient number of students selecting the option; for optional courses, 
Table 2.3 Current arrangement of subjects S1-S5

S1-S3 (i.e. the first three years of secondary education)

Subject 1 L1 (Years 1 and 2, five periods; Year 3, four periods)

Subject 2 L2 (Year 1, five periods; Years 2 and 3, four periods)

Subject 3 L3 (Year 1, five periods; Years 2 and 3, four periods)

Subject 4 Human Sciences (Years 1, 2 and 3, four periods)

Subject 5 Physical Education (Years 1, 2 and 3, four periods)

Subject 6 Mathematics (Years 1, 2 and 4, four periods)

Subject 7 Religion/Ethics (Years 1, 2 and 3, two periods)

Subject 8 Integrated Science (Years 1, 2 and 3, four periods)

Subject 9 Art (Years 1, 2 and 3, two periods)

Subject 10 Music (Years 1, 2 and 3, two periods)

Subject 11 ICT (Years 1 and 2, one period; Year 3, two periods - optional)

Subject 12 Latin (Years 2 and 3 - optional)

S4-S5 (i.e. the next two years of secondary education)

Subject $1 \mathrm{~L} 1$ (Years 4 and 5, four periods)

Subject 2 L2 (Years 4 and 5, three periods)

Subject 3 L3 (Years 4 and 5, three periods)

Subject 4 History (Years 4 and 5, two periods)

Subject 5 Physical Education (Years 4 and 5, two periods)

Subject 6 Mathematics (Years 4 and 5, either four or six periods)

Subject 7 Religion/Ethics (Years 4 and 5, one period)

Subject 8 Geography (Years 4 and 5, two periods)

Subject 9 Physics (Years 4 and 5, two periods)

Subject 10 Biology (Years 4 and 5, two periods)

Subject 11 Chemistry (Years 4 and 5, two periods)

Subject 12 Art (Years 4 and 5, two periods - optional)

Subject 13 Music (Years 4 and 5, two periods - optional)

Subject 14 ICT (Years 4 and 5, two periods - optional)

Subject 15 Latin (Years 4 and 5, two periods - optional)

Subject 16 Greek/Ancient Greek (Years 4 and 5, four/two periods - optional)

Subject $17 \mathrm{~L} 4$ (Years 4 and 5, four periods - optional)

Subject 18 Economics (Years 4 and 5, four periods - optional)

students are often given the choice to take the course in a vehicular language, if it is offered.

Currently, the number of courses using a student's 'non-dominant' language (i.e. not L1) as the language of instruction increases as the student progresses into secondary school. In particular, by the end of the first cycle of secondary school and into the second cycle there is a marked increase in the number of courses taught in L2; in the second cycle, options are also added, which likewise increases the chance of students 


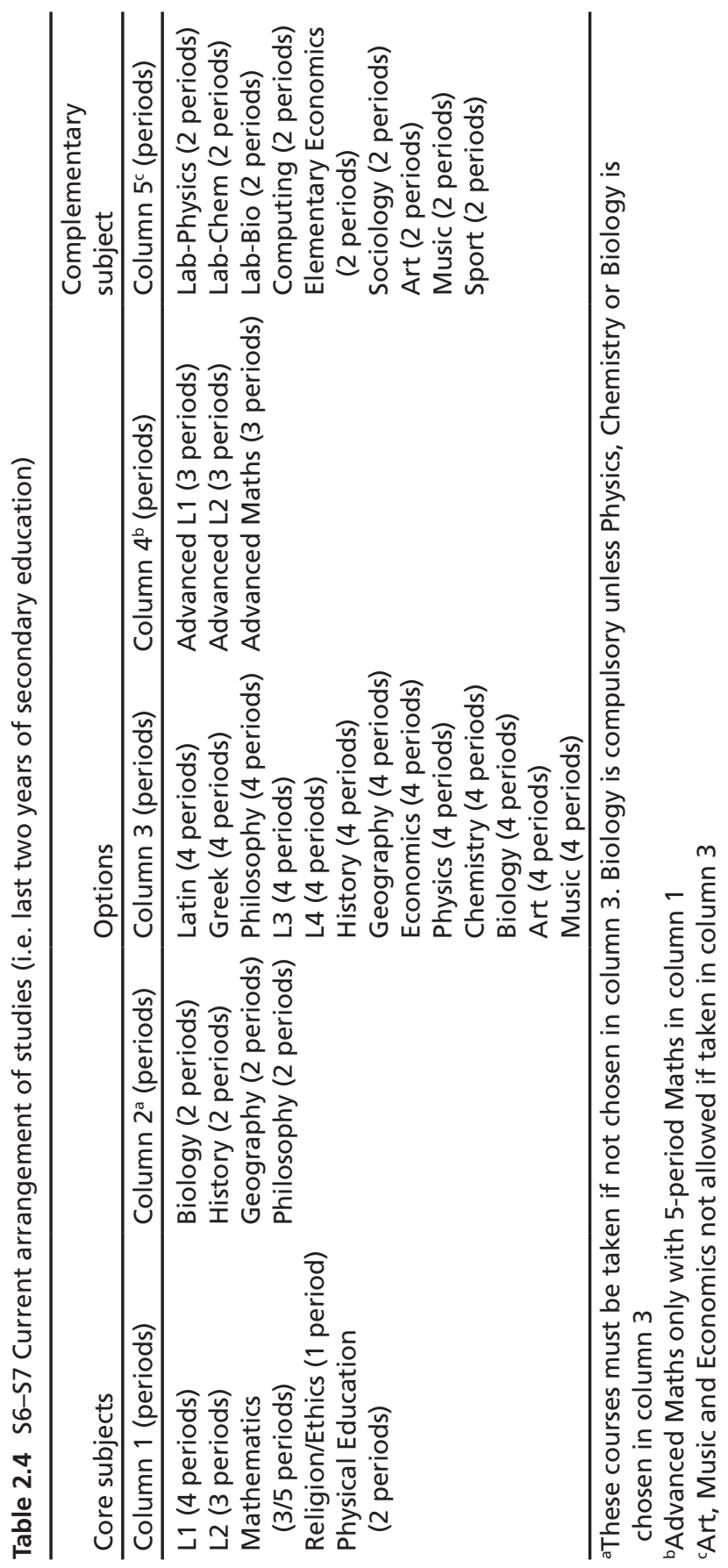


(particularly in smaller language sections) taking courses in their L2 or other vehicular language. Progression is meant to follow students' linguistic development, i.e. by S3 students are believed to be equipped with the skills to learn academic subjects in their L2.

In the current structure, students have some degree of personal choice over how much of their secondary education they undertake in their L2 or other languages. However, in most instances they are only able to exercise this control by confining their choice of subject options according to the specified language of instruction. This situation may favour multilingual students, but it can create difficulties for students who are not linguistically able due to learning difficulties or late entry into the system, and this is quite common given the mobility of the target population between countries and systems of education. There is also a wide range of experiences depending on the size or viability of the language section to which the student belongs, with students in smaller sections more often compelled to take courses in vehicular languages.

The proposals developed for the reorganisation of the upper secondary cycle (S6-S7) in February 2012 (cf. Board of Governors 2012) were the most far reaching and have thus been the most divisive. These were also the most thoroughly analysed by the working group, parents and other stakeholders. The current structure at S6-S7 is organised along the following lines (see Table 2.4). Core subjects must be offered. Options and complementary subjects may be offered if there are enough students in a section or school interested. (The minimum number of students required to create a course at this level is five). Some subjects are offered at both basic ( 2 periods, 3 for mathematics) and advanced levels ( 4 periods, 5 for mathematics). These include: mathematics, biology, history, geography and philosophy. Physics and chemistry are offered only in 4 period blocks (no 2-period option is offered). It is compulsory to choose history, geography and philosophy, either at a basic or at a superior level. It is compulsory to choose at least one scientific subject, i.e. biology, physics or chemistry. The possible choices are restricted by the Baccalaureate written and oral examination rules.

Any route through this complicated arrangement means that some form of specialisation prior to S6 and S7 is inevitable. Students are confronted with choices between disparate sets of options and even then, 
depending on the size of the school, the number of students opting for particular subjects, the types of L1 students choosing these subjects and the possibility of forming groupings within each school to accommodate this, they may not be given their first choices and thus have to settle for subjects which they did not choose.

With these arrangements, the following problems remain with regards to students' curricular arrangements: early specialisation; choosing between subjects which are not related; choosing between subjects which are related with the consequence that students are likely to be disappointed if they want to specialise in the humanities, the natural sciences or the social sciences; because of the arrangement of resources within the system or within the school (i.e. size of classes, L1 distributions of students, possibility of vertical groupings) they may be denied their first choices, with consequent effects on their motivation and the quality of their work; and by designating some subject areas as 2 period (restricted curriculum) or 4 period (extended curriculum) or 4 period plus (supplementary curriculum), different levels of learning and different types of students are created. This complicates and may distort the process of progression through a subject-based curriculum.

Traditionally courses at S6 to S7 level have been offered as core and elective modules. There are a number of reasons for this. In order to accommodate a broad and comprehensive curriculum conceived in strongly classified terms (i.e. where there are clear boundaries between subject areas), the only possible arrangements that can be made are to cluster some subjects together and offer choices within those clusters. This has the disadvantage that the clusters and the core subject areas, unless they are carefully designed, may not offer a comprehensive coverage of the curriculum and may allow a neglect of some of the key elements of the curriculum. For example, unless the core (which might include compulsory and clusters of optional subjects) is understood as having an overarching rationale, then it may not be fully comprehensive. What this means is that some students, especially those who specialise early, will be taught with a narrower curriculum.

There is always a problem with moving from traditional curriculum arrangements to new ones, because teachers, parents and students have over a period of time developed a familiarity with these arrangements, 
and change is always unsettling. There is also the issue that changing the arrangements for the curriculum may act to reduce the credibility of the European Baccalaureate and thus put at risk students' ability to access higher education. Another implication of changing the curriculum arrangements from a system that allows some choice, to one in which there is little choice, is that this reduced specialisation limits students' capacity to make choices for themselves and to study subjects and areas of the curriculum which have a special interest for them. This could have a negative effect on the motivation of the students.

\section{Curriculum Reforms}

A curriculum in essence is a planned programme of learning, and therefore if we are to understand it, we also have to develop a theory of learning. As a concept, learning is fundamentally related to knowledge, and therefore if we are thinking about learning and the practices of learning, we also need to make reference to what is to be and how it is learned, and typically what we are aiming at in such considerations is some form of knowledge. Philosophers usually divide knowledge into two principal categories, knowing-that and knowing-how. (They sometimes also add a third category, knowing-by-acquaintance, but this is not central to the argument that is being made.) The suggestion here is that these forms of knowledge are fundamentally different; in other words, there are strong and impermeable boundaries between them. Using a formulation from Robert Brandom (2000), we want to suggest that this is misleading, and that consequently some of the problems that these strong insulations have created can be resolved. This has implications for our theory of learning and knowledge-development and therefore for our curriculum theory that follows from it. What also follows from this is that in society these different forms of knowledge are given different statuses or have different attachments of importance, so, for example, vocational knowledge (broadly thought of as being about processes) is considered to be less important than academic knowledge (broadly understood as being about propositions), but these ascriptions of importance do not lie in the 
intrinsic nature of each knowledge form but in the way these knowledge forms are realised in particular societies.

Knowledge then, is fundamental to the three types of learning that have been identified: cognitive (relating to propositions), skill-based (relating to processes) and dispositional (relating to embodiments). Cognition comprises the manipulation of those symbolic resources (words, numbers, pictures etc.), which points to (though not necessarily in a mirroring or isomorphic sense) something outside itself, though the referent might also be construed as internally-related, or more specifically, as a part of an already established network of concepts (for example, cf. Brandom 2000). Skill-based knowledge is different from cognition because it is procedural and not propositional. Dispositional knowledge refers to relatively stable habits of mind and body, sensitivities to occasion and participation repertoires. Distinguishing between knowledge of how to do something (or process forms of knowledge), knowledge of something (or, in Brandom's terms, judging that claim in terms of its relations within and to a network of concepts) and embodied forms of knowledge (assimilating an action and being able to perform in the spaces associated with that action) is important; however, they are in essence all knowledgemaking activities, and furthermore as we will see can be formulated generically as acts of learning.

Knowledge is transformed at the pedagogic site, so it is possible to suggest that qualities such as: the simulation of the learning object, the representational mode of the object, its degree and type of amplification, control in the pedagogic relationship, progression or its relations with other learning objects (i.e. curriculum integration), the type of pedagogic text, relations with other people in the learning process, the organization of time (temporal relations) and types of feedback mechanism are fundamental components of this pedagogic transformation. What this means is that in the learning process, the learning object takes a new form as a result of changes to its properties: simulation, representation, amplification, control, integration, textual form, relations with other people, time and feedback. In contrast to some frameworks, i.e. Bernstein's sociolinguistic code theory (2002) or Maton's (2014) knowledge and knowers thesis, the sheer complexity of the possible pedagogic knowledge forms that this allows means that relations between pedagogic arrangements 
and social arrangements, and between these pedagogic arrangements and notions of identity-formation and social positioning, can only be tentatively sketched out.

Theoretical and contextual considerations impact, then, on how elements of teaching and learning are realised. Acknowledging this allows the identification of a number of learning models: assessment for learning, observation, coaching, goal-clarification, mentoring, peer learning, simulation, instruction, concept-formation, reflection, meta-cognitive learning, problem solving, and practice. And each of these in turn is underpinned by a particular theory of learning. What this means is that any model of learning that is employed is constructed in relation to particular views of how we can know the world and what it is. These models or learning sets (and this includes feedback mechanisms of a particular kind) give different emphases to the various elements of a learning process.

Choosing between these models depends on the nature and constitution of the learning object; in other words, the former is logically dependent on the latter. It also depends on the choice of learning theory that is made. These learning models have a crucial role to play (whichever one is chosen) in processes of learning and constitute elements of Bernstein's (2000) pedagogic device. In Chap. 3 we examine the organisation of language learning and the development of intercultural competence in the European school system.

Open Access This chapter is licensed under the terms of the Creative Commons Attribution 4.0 International License (http://creativecommons.org/licenses/ by/4.0/), which permits use, sharing, adaptation, distribution and reproduction in any medium or format, as long as you give appropriate credit to the original author(s) and the source, provide a link to the Creative Commons license and indicate if changes were made.

The images or other third party material in this chapter are included in the chapter's Creative Commons license, unless indicated otherwise in a credit line to the material. If material is not included in the chapter's Creative Commons license and your intended use is not permitted by statutory regulation or exceeds the permitted use, you will need to obtain permission directly from the copyright holder.

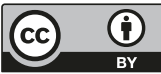

